\title{
DIVERS@!
}

\section{O LEGAL É “LEGAL”: APÓS UMA DÉCADA DAS DIRETRIZES CURRICULARES, QUE CURSO DE LETRAS QUEREMOS?}

LEGAL IS “COOL”: AFTER A DECADE OF THE CURRICULAR DIRECTIONS, WHICH LANGUAGE UNDEGRADUATION COURSE ARE WE LONGING FOR?

David José de Andrade Silva

\section{Resumo:}

O presente artigo pretende lançar a discussão sobre o curso de Letras, focado nas licenciaturas ofertadas pelas Instituições Federais de Ensino Superior à luz da legislação vigente, e provocar reflexões propositivas em busca de mudanças no curso para atender às demandas sociais atuais. Apesar do amparo e estímulo legal das legislações pós-Lei de Diretrizes e Bases da Educação Nacional (Lei 9.394/96), tais como as Diretrizes Curriculares para a Formação Inicial de Professores da Educação Básica em Cursos de Nível Superior (Parecer CNE/CP n ${ }^{\circ} 9$ de 08 de maio de 2001 e Parecer $\mathrm{CNE} / \mathrm{CP} \mathrm{n}^{\circ} 21$ de 6 de agosto de 2001) e as Diretrizes do Curso de Letras (Parecer CNE/CES n ${ }^{\circ} 492$, de 3 de abril de 2001), pouco avanço é percebido nos projetos pedagógicos dos cursos. Assim, serão analisados aqui duas grades curriculares de cursos de Letras/Inglês para verificar a presença das inovações pedagógicas propostas no âmbito legal.

Palavras-chave: Letras; inovações curriculares; legislação

Abstract:

The present paper aims to discuss the Language undergraduate courses, focused on the teacher education courses offered by the federal higher education institutions under the current legislation, and to trigger proposable reflections on the search of changes in these courses to fulfill the social needs. Despite the legal protection and stimuli from the laws after the Lei de Diretrizes e Bases da Educação Nacional (Law 9.394/96), such as the Diretrizes Curriculares para a Formação Inicial de Professores da Educação Básica em Cursos de Nível Superior (Parecer CNE/CP n ${ }^{\circ} 09$ de 08 de maio de 2001 and Parecer CNE/CES n ${ }^{\circ}$ 492, de 03 de abril de 2001), few advances are noticed in the courses curricula. So, through this article, two Language undergraduate teacher education courses will be analyzed to check the presence of pedagogical innovations proposed in the legal level.

Key-words: Language undergraduate courses; curricular innovation; law

Este trabalho gerou o simpósio de mesmo título apresentado no VI Seminário de Estudos Linguísticos e Literários da FAFIPAR no dia 20 de setembro de 2012 em Paranaguá/PR.

David José de Andrade Silva - Mestre, professor assistente da Universidade Federal do Paraná/ Setor Litoral - Rua Jaguariaíva, $\mathrm{n}^{\circ} 512$ - Matinhos/PR CEP: 83260-ooo

E-mail: davidufpr@yahoo.com.br 


\section{DIVERS@!}

\section{Introdução}

A criação de dispositivos legais para a realização de mudanças nos projetos pedagógicos dos cursos (PPC) superiores de licenciatura, decorrentes da mais recente Lei de Diretrizes e Bases da Educação Nacional n ${ }^{\circ}$ 9.394/96 (doravante LDB) é atribuição do Conselho Nacional de Educação (CNE), por meio do Conselho Pleno (CP) ou da Câmara de Ensino Superior (CES).

De 1997 até março de 2011 (data da última resolução da CES que envolve cursos de Letras), foram feitos estudos em diálogo constante com as instituições de ensino superior (IES), organizações científicas e comunidade escolar para a emissão de pareceres que contemplassem as aspirações sociais para organizar cursos de formação de professores atualizados para as demandas da sociedade atual e, consequentemente, embasasse teoricamente os projetos de resolução para regulamentar as propostas e dar segurança de implantação às IES.

Entretanto, somente medidas legislativas não garantem mudanças, e o preço pago por isso é uma dupla insatisfação. Por um lado, severas e constantes críticas nas mídias de massa que a classe do magistério sofre por não conseguir oferecer aulas de qualidade, fomentadas por "especialistas" no assunto e por pais preocupados com a educação de seus filhos - mas nem sempre participativos no acompanhamento dos mesmos. Por outro lado, recebo relatos pontuais dos licenciandos em campo de estágio sobre a situação da escola, onde professores sentem-se acuados e perdidos por assumirem responsabilidades que outrora não lhes eram outorgadas, como executar o papel do coordenador pedagógico ou um assistente social.

Alheios (ou não?) à repercussão dos diversos problemas que ocorrem na escola e na sala de aula, a formação de professores continua sendo um nicho de mercado lucrativo para as IES particulares (se não o fosse, não seria mais ofertada) e uma missão para o governo federal, haja vista os incentivos de diferentes ordens para fomentar a área, tais como: a expansão universitária em escala nacional; a criação da reserva de percentual de vagas nos Institutos Federais de Educação Profissional e Tecnológica (conhecidos como "IF" mais a sigla do estado ao qual pertence), principalmente para suprir a demanda de professores na área de Exatas; e o Programa Emergencial de Segunda Licenciatura do Plano Nacional de Formação de Professores 


\section{DIVERS@!}

da Educação Básica (PARFOR), para que os professores em exercício obtenham a formação mínima exigida pela LDB na(s) disciplina(s) que lecionam. Mas até que ponto esses investimentos e políticas públicas dão suporte a projetos pedagógicos consistentes, coerentes com uma educação voltada para a cidadania no século XXI?

Em meio a esse cenário, o presente artigo visa a discutir alguns aspectos legais que embasam o curso de Letras e suas respectivas habilitações, tendo como objeto principal as Diretrizes Curriculares Nacionais (DCN), suas legislações antecessoras e sucessoras. Procurarse-á trazer elementos previstos na legislação que permitem a flexibilidade curricular, a superação do paradigma dominante em prol do paradigma emergente (SANTOS, 2010, p.5859) e avaliar-se-á brevemente o que se conseguiu nos últimos dez anos de vigência das DCN de Letras e o que poderia se desenvolver para aprimorar os cursos relacionados à área a partir de experiências em andamento.

\section{Antes das Diretrizes Curriculares Nacionais}

As legislações que antecederam as DCN de Letras foram desdobramentos do espírito de retomada do estado democrático de direito no Brasil e da produção científica acumulada na área de estudos da linguagem e literatura. Contudo, ao mesmo tempo em que havia um desejo de transformação e justiça social através da educação e da cidadania, aspirações que embalaram a Constituição Federal de 1988 e a LDB de 1996, o ambiente universitário sempre alimentou a centralização do tripé ensino, pesquisa e extensão nas disciplinas ou em projetos particulares, não dando margem à integração de conhecimentos diversos e, assim, dificultando a construção de projetos pedagógicos oriundos de uma visão de totalidade para garantir o poder dos especialistas das microáreas (MORIN, 2002, p.40-46).

O Parecer CNE/CES n ${ }^{\circ}$ 776/97, cuja incumbência era a orientação para a elaboração das diretrizes curriculares dos cursos de graduação, trata exatamente das dificuldades históricas das universidades renovarem suas práticas pedagógicas e dos rumos desejados para a formação em nível superior. Os relatores iniciam o histórico do parecer nos seguintes termos (BRASIL/MEC/CNE/CES, 1997, p.1): 


\section{DIVERS@!}

(...) os currículos dos cursos superiores, formulados na vigência da legislação revogada pela Lei 9.394, de 20 de dezembro de 1996, em geral caracterizam-se por excessiva rigidez, que advém, em grande parte, da fixação detalhada de mínimos curriculares a qual resulta na progressiva diminuição da margem de liberdade que foi concedida ás instituições para organizarem suas atividades de ensino.

Deve-se reconhecer, ainda, que na fixação dos currículos muitas vezes prevaleceram interesses de grupos corporativos interessados na criação de obstáculos para o ingresso em um mercado de trabalho marcadamente competitivo, o que resultou nestes casos, em excesso de disciplinas obrigatórias e em desnecessária extensão do curso de graduação.

Ao longo dos anos, embora tenha sido assegurada uma semelhança formal entre cursos de diferentes instituições, o currículo mínimo vem se revelando ineficaz, para garantir a qualidade desejada, além de desencorajar a inovação e a benéfica diversificação da formação oferecida. (grifos meus)

A intencionalidade dos conselheiros aparentava, pelo desenho que se configurava no parecer, querer suplantar um passado de morosidade concentrado na lógica disciplinar dos currículos para promover maior autonomia às IES na organização de seus cursos em torno de uma concepção pedagógica integradora, modernizada e em diálogo com o mundo externo à academia. Assim, as diretrizes apoiar-se-iam nas orientações devendo considerar os seguintes aspectos (BRASIL/MEC/CNE/CES, 1997, p.2):

1) Assegurar, às instituições de ensino superior, ampla liberdade na composição da carga horária a ser cumprida para a integralização dos currículos, assim como na especificação das unidades de estudos a serem ministradas;

2) Indicar os tópicos ou campos de estudo e demais experiências de ensinoaprendizagem que comporão os currículos, evitando ao máximo a fixação de conteúdos específicos com cargas horárias pré-determinadas, as quais não poderão exceder 50\% da carga horária total dos cursos;

3) Evitar o prolongamento desnecessário da duração dos cursos de graduação;

4) Incentivar uma sólida formação geral, necessária para que o futuro graduado possa vir a superar os desafios de renovadas condições de exercício profissional e de produção do conhecimento, permitindo variados tipos de formação e habilitações diferenciadas em um mesmo programa;

5) Estimular práticas de estudos independente, visando uma progressiva autonomia profissional e intelectual do aluno;

6) Encorajar o reconhecimento de habilidades, competências e conhecimentos adquiridos fora do ambiente escolar, inclusive os que se refiram à experiência 


\section{DIVERS@!}

profissional julgada relevante para a área de formação considerada;

7) Fortalecer a articulação da teoria com a prática, valorizando a pesquisa individual e coletiva, assim como os estágios e a participação em atividades de extensão.

8) Incluir orientações para a condução de avaliações periódicas que utilizem instrumentos variados e sirvam para informar a docentes e a discentes acerca do desenvolvimento das atividades didáticas.

Apesar do contexto neoliberal em que o parecer foi concebido, influenciado pelas tendências educacionais europeias de educação superior (SANTOS, 2005, p.22), deve-se considerar o esforço da CES em: reduzir o poder das IES em definir carga horária e duração do curso, estabelecendo um teto de fixação de conteúdos em 50\% para ampliar a margem de autonomia do estudante de construir seu percurso acadêmico; valorizar o acúmulo de saberes e experiência de vida discente; incentivar práticas pedagógicas e processos avaliativos diferenciados, para além das aulas expositivas e das provas conteudistas. Em contrapartida, no que concerne à redução do tempo de estudo e a formação generalista, a interpretação equivocada (e mercadológica) gerou deturpações na oferta de licenciaturas (o curso de Pedagogia foi o mais atingido), mas esseé um assunto para outra oportunidade.

No caso específico das licenciaturas em Letras, além da rigidez, dos interesses corporativos, da discrepância curricular entre as IES e da ineficácia em promover inovações, havia uma dificuldade à parte: o conflito com o bacharelado e a necessidade de superar o patamar de apêndice do famoso esquema " $3+1$ " para se tornar um curso de formação de professores com características e identidade próprias. Nesse sentido, o Parecer CNE/CP n ${ }^{\circ}$ 009/2001 de 8 de maio de 2001 - as Diretrizes Curriculares Nacionais para a Formação de Professores da Educação Básica, em nível superior, curso de licenciatura, de graduação plena delimitam claramente o assunto (BRASIL/MEC/CNE/CP, 2001, p.47):

Nos cursos de formação para as séries finais do ensino fundamental e ensino médio, a inovação exigida para as licenciaturas é a identificação de procedimentos de seleção, organização e tratamento dos conteúdos, de forma diferenciada daquelas utilizadas em cursos de bacharelado; nas licenciaturas, os conteúdos disciplinares específicos da área são eixos articuladores do currículo, que devem articular grande parte do saber pedagógico necessário ao exercício profissional e estarem constantemente referidos 


\section{DIVERS@!}

ao ensino da disciplina para as faixas etárias e as etapas correspondentes da educação básica.

Qual seria, então, o perfil desejado para a formação docente consonante com o papel do professor previsto nos incisos I e VI do artigo 13 da LDB vigente, segundo os pareceristas? Pelas características arroladas abaixo (BRASIL/MEC/CNE/CP, 2001, p.4), houve sintonia com os valores destacados no Parecer $\mathrm{CNE} / \mathrm{CES} \mathrm{n}^{\circ}$ 776/97:

- orientar e mediar o ensino para a aprendizagem dos alunos;

- comprometer-se com o sucesso da aprendizagem dos alunos;

- assumir e saber lidar com a diversidade existente entre os alunos;

- incentivar atividades de enriquecimento cultural;

- desenvolver práticas investigativas;

- elaborar e executar projetos para desenvolver conteúdos curriculares;

- utilizar novas metodologias, estratégias e materiais de apoio;

- desenvolver hábitos de colaboração e trabalho em equipe.

As normatizações de base aparentavam seguir um fio condutor de legitimação, legal e teórico-conceitual, para a construção de projetos pedagógicos inovadores e, esperar-se-ia que as DCN de Letras continuassem na mesma direção, o que será tema do próximo tópico.

\section{As Diretrizes Curriculares Nacionais dos cursos de Letras}

A coesão e coerência demonstradas em favor de uma nova concepção educacional e de formação de professores perdem força quando, um mês antes da publicação do Parecer CNE/CP nº9/2001, é aprovado o Parecer CNE/CES n²492/2001 no dia 03 de abril de 2001, estabelecendo as Diretrizes Curriculares Nacionais dos cursos de Filosofia, História, Geografia, Serviço Social, Comunicação Social, Ciências Sociais, Letras, Biblioteconomia, Arquivologia e Museologia.

O primeiro fato a ser analisado é a aprovação "em massa" das diretrizes de dez cursos no mesmo documento. Poder-se-ia dizer que a mesma situação ocorreu novamente, pelo Parecer CNE/CES n ${ }^{\circ} 146 / 2002$ exatamente um ano depois, com a aprovação em bloco de outros onze 


\section{DIVERS@!}

cursos, sendo eles Direito, Ciências Econômicas, Administração, Ciências Contábeis, Turismo, Hotelaria, Secretariado Executivo, Música, Dança, Teatro e Design. Em ambos os casos, a maioria dos cursos é diretamente ligada às grandes áreas de Ciências Humanas e Ciências Sociais Aplicadas. Em ambos os casos, também, há a presença de cursos que tradicionalmente ofertam a modalidade de licenciatura. Todavia, ao analisar o histórico legislativo de cada graduação, constata-se a emissão, a partir de 2003, de novos pareceres individualizados para Direito, Ciências Econômicas, Administração, Ciências Contábeis, Turismo, Hotelaria, Secretariado Executivo e um novo parecer específico para Música, Dança, Teatro e Design. Ou seja, enquanto alguns avançaram na construção de melhorias, outros permaneceram estagnados no tempo em termos legais.

Outro fato, ainda comparando os Pareceres CNE/CES nº 492/2001 e o CNE/CES $\mathrm{n}^{\circ}$ 146/2002, é a diferença na redação dos mesmos. Enquanto o primeiro delineou sua proposta metodológica e conceitual em dois parágrafos, o segundo investiu doze páginas de preâmbulo para explicitar as bases comuns às graduações em tela, os objetivos possíveis de serem atingidos pelas IES ofertantes e as competências específicas de cada PPC. Não é só uma questão de pragmatismo ou objetividade na escrita. É nítida a discrepância entre ambas as comissões de trabalho e, notoriamente, entre os documentos.

Em comparação com os cursos pertencentes às Ciências Naturais, a graduação em Letras permanece em desvantagem: Ciências Biológicas, Física, Matemática e Química tiveram pareceres individuais, os quais foram emitidos seis meses após as DCN para formação de professores. Assim, os mesmos tiveram um período mínimo para refletir com maior cuidado o perfil profissional do bacharel e licenciado e organizá-los, à luz das novas legislações. Seria possível levantar a suspeita da existência de uma hierarquia universitária, onde cursos de certas áreas são tratados com esmero enquanto outros são lançados à "vala dos comuns"? O perfil discente do maior programa de intercâmbio internacional universitário do governo federal - o Ciências sem Fronteiras - pode responder a essa pergunta.

Alguns poucos elementos revelam que o histórico da construção do curso de Letras sob a nova égide legal careceu de maior atenção e, por que não, de participação mais ativa da 


\section{DIVERS@!}

comunidade universitária no debate para cobrar a redação de uma nova diretriz. É de se estranhar que praticamente metade dos cursos contemplados no Parecer CNE/CES n ${ }^{\circ}$ 492/2001, que também corresponde à grande parte da carga horária das disciplinas das séries finais do EF e do EM, não tenham sido rediscutidos após a emissão do Parecer CNE/CP $\mathrm{n}^{0}$ 09/2001 com o objetivo de agregar as questões relativas à formação inicial docente. No entanto, se a DCN permanece inalterada, também pode significar que seus interessados estejam satisfeitos com o texto. Vejamos isso a seguir.

A concepção de flexibilidade curricular apresentada nas DCN de Letras é ancorada nos seguintes princípios (BRASIL/MEC/CNE/CES, 2001, p.29):

- facultem ao profissional a ser formado opções de conhecimento e de atuação no mercado de trabalho;

- criem oportunidade para o desenvolvimento de habilidades necessárias para se atingir a competência desejada no desempenho profissional;

- dêem prioridade à abordagem pedagógica centrada no desenvolvimento da autonomia do aluno;

- promovam articulação constante entre ensino, pesquisa e extensão, além de articulação direta com a pós-graduação;

- propiciem o exercício da autonomia universitária, ficando a cargo da Instituição de Ensino Superior definições como perfil profissional, carga horária, atividades curriculares básicas, complementares e de estágio.

Os princípios expostos coadunam com os valores apregoados no Parecer CNE/CES $\mathrm{n}^{\circ} 776 / 97$, com destaque para a reafirmação do desenvolvimento da autonomia discente, a almejada articulação do tripé ensino-pesquisa-extensão e da graduação com a pós-graduação, e o respeito ao percentual máximo de fixação de conteúdos (50\%) para que as IES pudessem imprimir suas características peculiares e propiciar arranjos curriculares diversos para o estudante obter maior margem de trânsito em seu percurso acadêmico. À isso é complementado o entendimento de flexibilidade curricular como sendo a possibilidade de "eliminar a rigidez estrutural do curso; imprimir ritmo e duração ao curso, nos limites adiante estabelecidos; utilizar, de modo mais eficiente, os recursos de formação já existentes nas instituições de ensino 


\section{DIVERS@!}

superior" (BRASIL/MEC/CNE/CES, 2001, p.29). Estes três últimos itens, apesar da pouca clareza sobre seu impacto na flexibilidade do curricular, podem ser considerados como complementares aos princípios anteriores. Ainda nesse quesito, o parecer chama a atenção para o papel dos docentes e do colegiado do curso (BRASIL/MEC/CNE/CES, 2001, p.29-30), que evoca as atribuições dos professores no artigo 13 e a gestão democrática no artigo 56 da LDB. Dos primeiros, requer-se "o desdobramento do papel de professor na figura de orientador, que deverá responder não só pelo ensino de conteúdos programáticos, mas também pela qualidade da formação do aluno". Ao segundo compete "a concepção e o acompanhamento da diversidade curricular que a IES implantará".

Contudo, a flexibilidade curricular é comprometida no item "Estruturação do Curso" da DCN (BRASIL/MEC/CNE/CES, 2001, p.31), no qual é colocado que "Os cursos devem incluir no seu projeto pedagógico os critérios para o estabelecimento das disciplinas obrigatórias e optativas das atividades acadêmicas (...)”. A restrição da organização do PPC somente à perspectiva disciplinar vai de encontro à busca pela inovação e renovação no ensino superior e colide com as DCN de formação de professores (BRASIL/MEC/CNE/CP, 2001, p.52):

Ao elaborar seu projeto curricular, a equipe de formadores deve buscar formas de organização, em contraposição a formas tradicionais concentradas exclusivamente em cursos de disciplinas (...)

(...) é preciso instituir tempos e espaços curriculares diversificados como oficinas, seminários, grupos de trabalho supervisionado, grupos de estudo, tutorias e eventos, atividades de extensão, entre outros capazes de promover e, ao mesmo tempo, exigir dos futuros professores atuações diferenciadas, percursos de aprendizagens variados, diferentes modos de organização do trabalho, possibilitando o exercício das diferentes competências a serem desenvolvidas.

A DCN de Letras não somente manteve uma concepção retrógrada de projeto pedagógico, mas também dos profissionais que forma. O perfil esperado do formando, tanto no bacharelado quanto na licenciatura, é tido como único, mesmo sendo de naturezas e objetivos diferentes. Esse pode ser um indicador da dificuldade de superar a visão de que, para ser um 


\section{DIVERS@!}

bom professor de línguas, basta saber a língua, pois o ofício de professor é "vocacional" ou exige apenas o conhecimento de algumas técnicas e métodos de ensino. A DCN coloca que (BRASIL/MEC/CNE/CES, 2001, p.30):

o profissional em Letras deve ter domínio do uso da língua ou das línguas que sejam objeto de seus estudos, em termos de sua estrutura, funcionamento e manifestações culturais, além de ter consciência das variedades lingüísticas e culturais. Deve ser capaz de refletir teoricamente sobre a linguagem, de fazer uso de novas tecnologias e de compreender sua formação profissional como processo contínuo, autônomo e permanente. (...) O profissional deve, ainda, ter capacidade de reflexão crítica sobre temas e questões relativas aos conhecimentos lingüísticos e literários. (grifos meus)

O espaço para discussão aqui é limitado, mas constar no parecer que o profissional de Letras deve ter "domínio do uso da língua" alimentaria um bom debate sobre o entendimento dos pareceristas da palavra "domínio". Logo, citarei outros aspectos do perfil, como o predomínio dos estudos linguísticos sobre os literários, a menção ao uso das Novas Tecnologias da Informação e Comunicação (NTIC) e a ausência total de qualquer palavra que remeta ao exercício do magistério. A maioria dos cursos geralmente se organiza com uma carga horária nos estudos literários inferior aos de estudos linguísticos, a não ser nos casos em que a habilitação é específica para a área. O trabalho com as NTIC, salvo melhor juízo, ainda está aquém de sua potencialidade, tanto para bacharéis quanto para licenciados, sendo estes ainda com o agravante de a maior rede de educação formal (as escolas públicas) estarem inserindo vagarosamente uma estrutura tecnológica compatível com a comunidade escolar. E o ápice do perfil do egresso é a desconsideração da docência que, ouso afirmar, é onde se concentra a maior parte dos estudantes de Letras. Esse é um ônus que a concepção do curso carrega por não ter contemplado o Parecer $\mathrm{CNE} / \mathrm{CP} \mathrm{n}^{\circ}$ 09/2001 e, até que se altere, os professores em formação permanecerão, embora sendo maioria, à sombra dos bacharéis. Mas ainda havia uma esperança: o exercício da autonomia universitária para desenhar o curso.

As IES teriam o poder de preencher as lacunas deixadas pelas DCN de Letras em relação às licenciaturas e se apropriar da missão de formar professores de língua, conforme a própria 


\section{DIVERS@!}

diretriz propõe, "compromissado com a ética, com a responsabilidade social e educacional, e com as conseqüências de sua atuação no mundo do trabalho" (BRASIL/MEC/CNE/CES, 2001, p.31). No próximo tópico abordar-se-á, então, a estrutura curricular dos cursos de Letras do Paraná em Instituições Federais de Ensino Superior (IFES) criadas no processo de expansão universitária após as DCN.

\section{Os cursos de Letras do Paraná pós-DCN}

O Brasil vive um momento histórico no processo de expansão de educação universitária, tecnológica e técnica, principalmente pela postura do Governo Federal pós-era Lula de tomar para si a frente dos rumos do ensino brasileiro. O estado do Paraná, por exemplo, foi contemplado com: um novo campus da UFPR (Setor Litoral de Matinhos); a conversão do Centro Federal de Educação Tecnológica do Paraná (CEFET-PR) em Universidade Tecnológica Federal do Paraná (UTFPR) com a inclusão de novos campi; a criação da Universidade Federal da Integração Latino-Americana (UNILA) em Foz do Iguaçu; a criação da Universidade Federal da Fronteira Sul (UFFS) com os campi de Realeza e Laranjeiras do Sul; e o desmembramento da Escola Técnica Federal da UFPR (ETUFPR) para transforma-se em Instituto Federal do Paraná (IFPR), com 14 campi (sendo um em Paranaguá). Para a análise da proposta curricular, selecionamos os seguintes cursos: Letras/ Português-Inglês, da UTFPR (campus Curitiba); e Letras/ Português-Espanhol (noturno), da UFFS. O critério de escolha é o fato dessas IES e respectivas licenciaturas terem sido ou recém-criadas no projeto de políticas públicas expansionistas do MEC (UFFS) ou recém-ingressar nesse campo do conhecimento (a UTFPR nunca teve um curso de Letras até 2008) o que, teoricamente, as tenderiam a adotar fortemente as orientações e diretrizes atuais, ao contrário das demais instituições já existentes e com uma história consolidada.

A metodologia de análise das matrizes curriculares concentrar-se-á:

1) no levantamento da quantidade de atividades obrigatórias e optativas, sem contabilizar as horas de estágio supervisionado e as 200 horas de atividades de "outras formas de atividades 
acadêmico-científico-culturais" da Resolução CNE/CP nº2/2002 de 19 de fevereiro de 2002; 2) na classificação, separação e contabilização das atividades em disciplinas e outros componentes curriculares específicos da área de estudos da linguagem e da literatura; 3) no levantamento da quantidade de atividades curriculares voltadas à formação docente e de prática pedagógica que não sejam o estágio supervisionado; 4) na presença de práticas que contemplem o uso das NTIC. A partir desses parâmetros, espera-se levantar: 1), o grau de flexibilidade curricular; 2) se na organização curricular predomina a disciplina (serão consideradas disciplinas todas as atividades em que não conste alguma palavra que dê a entender o contrário) e em qual área, estudos linguísticos ou literários, se concentra maior carga horária; 3) se há equilíbrio entre a carga horária destinada aos conteúdos específicos da área de Letras e os conteúdos de formação docente; 4) o tempo destinado à reflexão sobre as NTIC. Cabe ressaltar que somente pelos documentos disponibilizados na internet não é viável fazer julgamentos ou avaliações minuciosas e aprofundadas sobre os cursos, e nem é esta a intenção, mas é possível fazer um quadro para se ter uma visão panorâmica dos cursos.

O curso ofertado pela UTFPR foi criado em 2008, tem 3.770 horas de duração distribuídas em 8 semestres e é estruturado em disciplinas/unidades curriculares. Conforme a Tabela 1 abaixo, a distribuição de carga horária é:

\begin{tabular}{|c|c|c|}
\hline Parâmetros & & \\
\hline 1) Atividades Curriculares & Quantidade & Carga horária total \\
\hline Obrigatórias & 61 & 2750 \\
\hline Optativas & $\stackrel{4}{4}$ & $\stackrel{120}{\text { Cargahoríriatotal }}$ \\
\hline Disciplinas' & 56 & 2570 \\
\hline $\begin{array}{l}\text { Outras (laboratórios, oficinas, } \\
\text { seminários, ete.) }\end{array}$ & 6 & 180 \\
\hline Estudos Linguísticos & 14 & 540 \\
\hline Estudos Literários & 19 & 765 \\
\hline 3) Formação docente & Quantidade & Carga horária total \\
\hline Disciplinas & 12 & 390 \\
\hline $\begin{array}{l}\text { Outras (laboratórios, oficinas, } \\
\text { seminários, ete.) }\end{array}$ & o & 0 \\
\hline $\begin{array}{l}\text { 4) Novas Teenologias da } \\
\text { Informação e Comunicação } \\
\text { (NTIC) }\end{array}$ & Quantidade & Carga horária total \\
\hline Disciplinas & 1 & 30 \\
\hline $\begin{array}{l}\text { Outras (laboratórios, ofieinas, } \\
\text { seminários, ete.) }\end{array}$ & 0 & 0 \\
\hline
\end{tabular}




\section{DIVERS@!}

O curso da UFFS foi criado há quase dois anos, tem 3.855 horas de duração distribuídas em 10 semestres e é estruturado, de acordo com a nominação que consta na matriz curricular, em componentes curriculares. Na Tabela 2, a composição da carga horária:

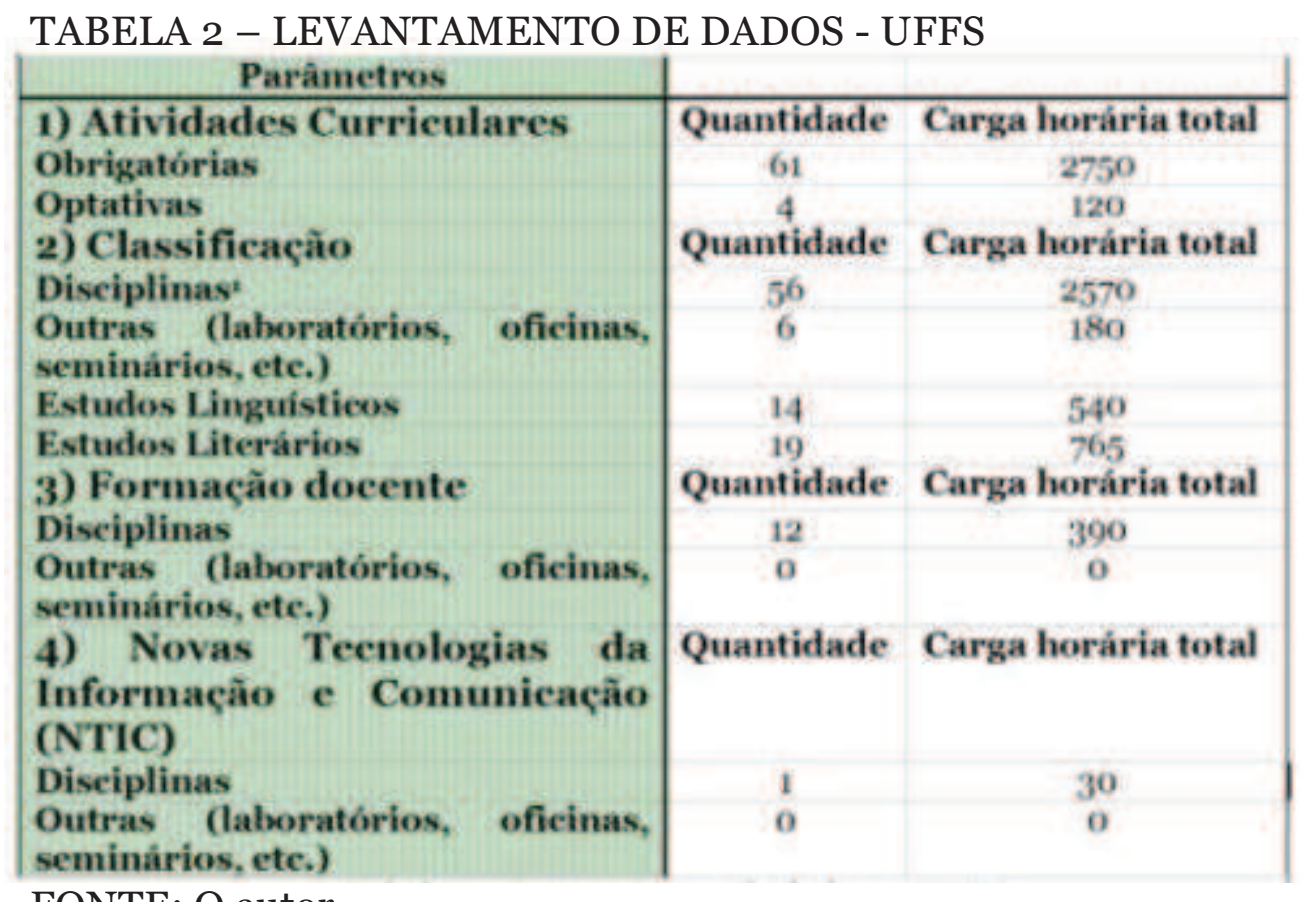

FONTE: O autor

Por meio dos dados apresentados, é possível perceber que a UTFPR oferta mais atividades diferenciadas do que a UFFS (apesar daquela ter uma carga horária total menor), mas a perspectiva de organização curricular por disciplinas predomina.

A UTFPR construiu um curso mais equilibrado em sua carga horária obrigatória nos estudos linguísticos (19,63\%), literários (27,82\%) e pedagógicos (14,18\%) em comparação com a UFFS (31,65\%, 23,11\% e 6,53\%, respectivamente), considerando-se a segunda IES com carga horária de formação docente preocupante, pois oferta apenas uma disciplina a mais do que na época do currículo mínimo (PAIVA, 2003, p.13). Além do equilíbrio maior nas discussões de língua, literatura e formação docente, a UTFPR também propicia aos discentes maior flexibilidade curricular pelas disciplinas optativas em relação à UFFS, mas ainda são percentuais irrisórios da carga horária do curso - 3,18\% e 1,5\%, respectivamente. Neste aspecto, fica a dúvida se há um conflito entre a autonomia universitária para a definição dos conteúdos e a orientação das diretrizes de que o máximo de conteúdos específicos a serem fixados não 


\section{DIVERS@!}

poderia exceder 50\% (BRASIL/MEC/CNE/CES, 1997, p.2). Em relação às NTIC, ambas as instituições ofertam, mas também com carga horária baixa.

\section{Considerações Finais}

O presente artigo propôs-se a discutir duas grades curriculares de cursos de Letras/ Inglês de universidades federais criados após a promulgação das DCN de Letras. A primeira parte tratou do período pós nova LDB de 1996, quando o CNE/CES buscou oferecer instrumentos legais às IES que avançassem na flexibilidade curricular e em um perfil discente voltado para a polivalência e autonomia. A segunda parte analisou as DCN de Letras em si e a comparou com outros cursos de formação de professores para a Educação Básica, constatandose que, enquanto alguns cursos conseguiram dar continuidade à discussão sobre os cursos e aprofundar os conceitos e objetivos norteadores, Letras permaneceu estagnada no tempo. Por fim, foram apresentadas duas grades curriculares de cursos de Letras para exemplificar os pontos de progresso em relação ao modelo do currículo mínimo anterior à nova LDB e as dificuldades de contemplar as proposições do Parecer CNE/CES n ${ }^{\circ}$ 776/97 no que concerne à novos arranjos curriculares.

Mediante o exposto, é possível perceber que os dez anos transcorridos da aprovação das DCN de Letras parecem não ter influenciado a organização curricular no sentido de promover práticas inovadoras, mesmo estas sendo estimuladas desde o final dos anos de 1990. Também não há, aparentemente, um movimento para rediscutir as DCN, tal qual outros cursos fizeram, o que pode indicar um estado de passividade ou satisfação dos atores diretamente interessados.

Há algumas iniciativas institucionais isoladas, como o curso de Licenciatura em Linguagem e Comunicação do Setor Litoral da UFPR, cuja flexibilidade curricular atinge 40\% da carga horária total do curso na oferta dos módulos de: Interações Culturais e Humanísticas, voltado para a formação cultural em contraponto ao tecnicismo dominante nas IES, que é organizado em temas e construído a partir da construção coletiva dos sujeitos (estudantes, professores, técnicos e comunidade); e os Projetos de Aprendizagem, criados a partir dos interesses pessoais dos estudantes para a construção de seu percurso acadêmico, com o compromisso de desenvolver alguma ação na região atendida pelo Setor Litoral (os sete 
municípios litorâneos com extensão ao Vale do Ribeira). Essas iniciativas merecem ser pesquisadas e divulgadas nos fóruns competentes para promover discussões e, por que não, as mudanças desejadas (ou não?) na formação de professores de línguas.

\section{Nota}

1. Não foram computadas as atividades optativas neste cálculo por ser prerrogativa do estudante escolher, podendo ser uma disciplina ou não. Nos estudos linguísticos, foram consideradas unidades didáticas cujo título se referisse a algo específico desse campo, como "morfologia”, "sintaxe", "semântica”. Portanto, as línguas estrangeiras só foram inseridas no cômputo dos estudos linguísticos quando constavam as palavras-chave citadas.

\section{Referências}

BRASIL. Lei 9.394/96 de 20 de dezembro de 1996. Estabelece as diretrizes e Bases da Educação Nacional. Diário Oficial [da] República Federativa do Brasil. Brasília, DF, 23 de dez. de 1996.

BRASIL. Conselho Nacional de Educação/ Câmara de Educação Superior. Parecer n ${ }^{\circ} 776$ de 3 de dezembro de 1997. Orientação para as diretrizes curriculares dos cursos de graduação.

BRASIL. Conselho Nacional de Educação / Câmara de Educação Superior. Diretrizes Curriculares Nacionais dos cursos de Filosofia, História, Geografia, Serviço Social, Comunicação Social, Ciências Sociais, Letras, Biblioteconomia, Arquivologia e Museologia. Parecer nº 492 de 3 de abril de 2001.

BRASIL. Conselho Nacional de Educação / Conselho Pleno. Diretrizes Curriculares Nacionais para a Formação de Professores da Educação Básica, em nível superior, curso de licenciatura, graduação plena. Parecer $n^{\circ} 09$ de 8 de maio de 2001.

BRASIL. Conselho Nacional de Educação/ Conselho Pleno. Institui a duração e carga horária dos cursos de licenciatura, de graduação plena, de formação de professores da Educação Básica em nível superior. Resolução ${ }^{\circ} \mathrm{O} 2 / 2002$ de 19 de fevereiro de 2002. 
BRASIL. (2011). Conselho Nacional de Educação / Conselho Pleno. Estabelece diretrizes para a obtenção de uma nova habilitação pelos portadores de Diploma de Licenciatura em Letras. Resolução ${ }^{\circ}{ }^{\circ}$ de 18 de março de 2011.

MORIN, E. Os sete saberes necessários à educação do futuro. São Paulo: Cortez, 2002. 6.ed.

PAIVA, V.L.M.O. A LDB e a legislação vigente sobre o ensino e a formação de professor de língua inglesa. In: STEVENS, C.M.T e CUNHA, M.J. Caminhos e Colheitas: ensino e pesquisa na área de inglês no Brasil. Brasília: UnB, 2003. p.53- 84. Disponível em: http://www.veramenezes.com/publicacoes.html (Acessado em $15 / 08 / 2012)$.

SANTOS, B.S. A universidade no século XXI: para uma reforma democrática e emancipatória da universidade. São Paulo: Cortez, 2005. 2 ed.

Um discurso sobre as ciências. São Paulo: Cortez, 2010. 7.ed.

UNIVERSIDADE FEDERAL DA FRONTEIRA SUL. Matriz curricular do curso de Licenciatura em Letras/ Português-Espanhol. Disponível em:

$<$ http://www.uffs.edu.br/index.php?option=com_docman\&task=doc_download\&gid=319\&Itemid=>Acesso em: 15 out. 2012.

UNIVERSIDADE FEDERAL DO PARANÁ. SETOR LITORAL. Matriz curricular do curso de Licenciatura em Linguagem e Comunicação. Disponível em:

http://www.litoral.ufpr.br/sites/default/files/Resolu\%C3\%A7\%C3\%A30\%2018-12-CEPE\%20\%20Fixa\%20o\%2oCurr\%C3\%ADculo\%2oPleno\%2odo\%2oCurso\%2oLINCOM\%20\%28de\%2019-o612\%29.pdf Acesso em: 10 maio 2013

UNIVERSIDADE TECNOLÓGICA FEDERAL DO PARANÁ. Matriz curricular do curso de Licenciatura em Letras/ Português-Inglês, campus Curitiba. Disponível em:

<http://www.utfpr.edu.br/curitiba/cursos/licenciaturas/Ofertados-neste-Campus/letras-portuguesingles/matriz> Acessado em: 15 out. 2012. 